\title{
INCLUSIVE HISTORIES FOR INCLUSIVE FUTURES: INTERACTIONS AND ENTANGLEMENTS THEN AND NOW
}

\author{
DOI: http://dx.doi.org/10.17159/2223-0386/2016/n15a4 \\ Jared McDonald \\ Department of History, University of the Free State \\ mcdonaldjr@ufs.ac.za
}

\section{Abstract}

This article makes a case for the production and dissemination of inclusive histories in public dialogue and public spaces of history consumption, including classrooms, lecture halls, monuments and textbooks. Inclusive histories are plural and multi-perspectival, meaning that interactions, overlapping phenomena and entanglements between various collectives at both the state and sub-state levels are emphasised. The discussion contends for a national historical narrative that encourages social accord rather than social fracturing without projecting a mythical reconciliatory motif onto the past. It also cautions against the pursuit of sanitised versions of the past and reflects on how discourses of victimhood and indigeneity put at risk the prospects for inclusive futures in pluralistic societies. The article argues that publically consumed commemorations and interpretations of the South African past should reflect the multiplicity of histories and peoples that inhabit the national space. It also suggests that re-telling South Africa's collective past in innovative rather than destructive ways, and in a manner that embraces the inclusive ethos of its constitutional democracy, will assist in producing a more inclusive historical narrative. The arguments in this article are intended to challenge and motivate those engaged in narrating history - amateur historians, history teachers, history learners, heritage practitioners, and textbook publishers - to represent the past in ways that promote plurality and multi-perspectivity in the present and for the future.

Keywords: South Africa; Inclusive histories; History education; Identity; Belonging; Multi-perspectivity; Critical citizenship; Entanglement.

\section{Introduction}

This article argues for an inclusive epistemological approach to the production and dissemination of South African history in various teaching forums and 
public spaces, including classrooms, lecture halls, monuments and textbooks. The discussion raises important questions for all those working in the history profession and is intended to inspire new pedagogical interventions in the discipline (even though the practicalities of how such interventions may be achieved in the classroom or lecture hall are beyond the scope of this paper). The discussion is inspired by recent events surrounding public commemorations of the past in South Africa. It seeks to make a timely input to these public contests relating to identity, belonging and representations of the past. The discussion is intended to challenge and motivate those engaged in narrating history - in particular history teachers and learners - to represent the past in ways that promote plurality and multi-perspectivity in the present and for the future.

Perhaps the most important reason for studying the past is to glean insights into the present and how it has come to be. The study of the past does, however, serve several other important roles. For example, identities, both individual and communal, are based on some understanding of their origins, even if factually tenuous. The stories we tell ourselves about ourselves are informed by the past and the plotting of time into a narrative is what transforms the past into history (Neem, 2011:48). As Ahonen (2001:179) notes, "past and present become comprehensible to a community through narratives rather than more analytical modes of knowledge." It is for this reason that history provides another crucial dimension to our understanding of the present: it sheds light on the influences, values and norms shaping our current interpretations and representations of the past. The way we speak about the past tells us something about who we are in the present. This is because the past is not history - "the past cannot be the same as narration about it" - but rather history is an interpretation of the past that is bound and shaped by the present (Morgan, 2015:371). The past is a strange place, a contested space, a foreign country, to which we cannot travel. The past cannot be reconstructed. It can only ever be partially re-presented based on the traces it has left us.

While professional historians are subject to the standards and values of their academic discipline: to imagine and re-present the past in as accurate and non-biased a way as possible, they do not have exclusive claim to the past. History cannot be monopolised by anyone or by any one group. It is open to re-imaginings and re-presentations that may not prioritise accuracy, balance, or fairness. Therefore, it is important to recognise that there is a difference 
between history as an academic discipline and history as a public enterprise. Public history is not bound by the same professional criteria that apply to the academic discipline and is, as such, susceptible to misrepresentation, sweeping generalisations, inaccuracies and even blatant manipulation. As Macmillan (2008:36) has observed, bad histories tend to be bad because they tell "only part of complex stories"; bad histories are also guilty of making "sweeping generalisations for which there is not adequate evidence and [which] ignore awkward facts that do not fit." Those working within the history profession - including amateur historians, school teachers and heritage practitioners have a responsibility to "raise public awareness about the past in all its richness and complexity" and contest the one-sided, false histories that compete for space in the public domain (Macmillan, 2008:37).

History is not an exact science. Its conclusions change over time and with time. The recent South African past reveals clues to this fact. As Nuttall and Wright (2000:30) have observed, in South Africa "historical scholarship [has] had a persuasive political purpose, giving voice to selected grand narratives of the region's conflictual past, and so feeding into contemporary politics." These grand narratives have been shaped by the motifs of conflict and struggle, and triumph after the advent of democracy in 1994. In response to these changes, South Africa's historical narrative has tended to shift towards embracing a reconciliatory tone. This was especially so during the Mandela years. The country's rapidly growing tourism industry in the aftermath of the transition to democracy also created demand for a reconciliatory history; as is evident in several places of historical significance, such as Robben Island and the KwaZulu-Natal Battlefields, in particular, the site of the Battle of Blood River (Nuttall \& Wright, 2000:31).

The problem with a reconciliatory approach is that the past is at risk of becoming "a source of comfort rather than a source of truth" (Torbakov, 2011:210). The past may be reduced to a teleological narrative that lauds the perceived inevitable triumph of good (the liberation struggle and subsequent political status quo) over evil (colonialism and apartheid), even as it seeks to emphasise examples of past co-operation between conflicting parties and interests in a bid to stoke hope for co-operation in the future. Nuttall and Wright (2000:31) remind us, however, that it is not necessarily desirable for South African historians "to make a shift to producing reconciliation history", especially as they are "compelled to refer to archival sources where they continue to find more evidence for conflict than co-operation." 
Recent events suggest that the heretofore reconciliatory approach to the past is failing to resonate with many ordinary South Africans. Dissatisfaction with the pace of socio-economic transformation has been brought to bear on numerous reminders of the conflictual nature of the South African past that some find offensive and misplaced in the new democratic dispensation. Statues in particular have become the target of this frustration. In early 2015, several statues of colonial- and apartheid-era figures were vandalised amidst growing demands that they be removed. This was epitomised by the "Rhodes Must Fall" campaign that demanded the removal of the statue of Cecil John Rhodes from the Upper Campus of the University of Cape Town, which succeeded in April 2015. Statues, like books, are not inanimate objects. They stand for human thoughts, ideas and actions. Our "built environment conveys historical meaning" and while South Africa's urban and rural landscapes still bear deeply entrenched signs of the country's segregationist past, statues are easier to focus one's anger and frustration on in an attempt to initiate some form of change (Ahonen, 2001:187).

The removal of a statue is not likely to bring about the kind of structural transformation that is needed, but the act is far from insignificant. The vandalising and removal of statues represents the attempted erasure or expunging of parts of the South African past and as such, de-legitimises the presence of the ideas and people the statues symbolise. While the ideas represented by the statues that have been targeted for removal may no longer be in vogue and worth condemning, this is only because of the passage of time and the changes that have occurred in the interim. Without a sense of change over time, the past risks being reduced to a thin residue of a narrative that will obscure and distort any meaningful historical understanding of the present. There are enormous risks involved in trying to purge aspects of the past; in attempting to establish a sanitised version of the past; one that only tells good, heroic stories, or stories that stress the victimhood of those doing the narrating.

Be that as it may, "a new future requires a new past" and 22 years into the era of democratic rule this challenge remains very much alive for the South African collective, with the socio-economic legacies of the past still firmly entrenched (Torbakov, 2011:212). But if a reconciliatory history is inadequate for the reasons already mentioned, what type of history ought to be pursued instead? This article makes a case for the production and dissemination of inclusive histories in public dialogue and public spaces of history consumption, as well 
as spaces of commemoration. Inclusive histories are plural, multi-perspectival and trans-cultural, meaning that interactions, overlapping phenomena and entanglements between various collectives at both the state and sub-state levels are emphasised.

The following discussion contends for a national historical narrative that encourages social accord rather than social fracturing without projecting a mythical reconciliatory motif onto the past. It also cautions against the pursuit of sanitised versions of the past and reflects on how a deeply-rooted sense of victimhood can still accommodate the anti-hero. The article argues that publically consumed commemorations and interpretations of the South African past should reflect the multiplicity of histories and peoples that inhabit the national space. It also suggests that re-shaping and re-telling the collective past in innovative rather than destructive ways will assist in producing a more inclusive historical narrative and in turn, promote the emergence of a more inclusive national identity (Ndlovu, 2013).

\section{Entanglement and the dangers of exclusivist narratives}

Nuttall (2009:1) describes entanglement as the "condition of being twisted together or entwined". Furthermore, entanglement refers to "a relationship or set of social relationships that is complicated, ensnaring, in a tangle, but which also implies a human foldedness." Nuttall suggests that entanglement offers a conceptual rubric by which South Africans can begin to face up to the challenges of the post-apartheid era (2009:11). Though differences, especially as they relate to inequalities, are often accentuated - understandably so in the current socio-economic setting - the "intricate overlaps that mark the present, and, at times, and in important ways, the past, as well" tend to be forgotten. An interpretive approach to the past that uses entanglement as a lens is a means "by which to draw into our analyses those sites in which what was once thought of as separate - identities, spaces, histories - come together or find points of intersection in unexpected ways" (Nuttall, 2009:11).

The concept of entanglement neatly sums up the South African historical experience and provides a novel way in which to construct narratives of the past. Contrary to a reconciliatory approach, entanglement does not shy away from acknowledging moments and processes of exploitation, dispossession, violence and conflict. It also avoids highlighting instances of co-operation and collaboration to the neglect of the predominant themes of dispossession 
and discrimination that we encounter when looking back. Therefore, it is an important constituent element of inclusive histories. As a conceptual approach to the past, entanglement is able to accommodate a multitude of small narratives, which together may become the basis for a new, inclusive grand narrative that acknowledges just how complexly historied the South African national space is.

This is particularly pertinent given ongoing debate surrounding the style, content and use of history textbooks in the country. History is an identity subject and is used for identity-making. As such, any grand narrative that is disseminated through a national school history curriculum will project an identity onto learners. The temptation may be to impart a uniform identity, inspired by the invented attributes and qualities of the nation-state. Though Chisholm (2008:356) points out that "there is no causal connection between history textbooks, their constructions and uses and the emergence of particular forms of identity or attitudes amongst the general populace", the textbook narrative does provide a sense of the political prerogatives influencing the transmission of historical knowledge.

The invented attributes and qualities of the collective tend to be imbued with a sense of inevitability in any master narrative that serves political interests, providing necessary justification for the status quo; the present was always meant to be. As Ahonen (2001:179) reminds us, however, "the identity of a community is not an immutable essence, but rather a dynamic process." In addition, "whatever continuity we may choose to impose on the past is a human construct and, therefore, of necessity situated in a dynamic, ephemeral, and potentially fragile cultural time-space" (Allen, 2000:295). It is for these reasons that history textbooks, along with all other forms and productions of history, should promote an open process of critical engagement rather than an identity politics (Ahonen, 2001:190).

In multi-ethnic, multi-cultural, multi-religious, multi-lingual societies which are becoming increasingly common across the world - any narrative that imposes a uniform identity on the state collective will inadvertently impart an exclusivist vision of the past, and in turn the present and future. Nationalist historiographies are not only inadequate in the age of globalisation, but potentially dangerous. Nationalist, or exclusivist, narratives are morally and politically problematic in that they tend towards the essentialising of the nation's identity (Nyamnjoh, 2007). In doing so, those left out of the narrative are also excluded from the historical community, delegitimising their presence 
in the both the past and the present. Attempts at the monopolisation of the past by any group - be it an ethnic majority or a political elite - are flawed in an increasingly mobile global society in which conditions of hybridity and syncretism are becoming the new normal. Even so, this does not stop such attempts from being made. This is because "a critical community is harder to govern than a community with a uniform identity" (Ahonen, 2001:190).

However, the consequences of this will become more and more destabilising in a globalising world (Andreasson, 2010). Narratives of the past are going to have to incorporate the changing realities of the "Global Village", especially at the level of the nation-state where the politics of belonging and identity are most contested. Nation-states all have a moment of origin, whether geographical, mythical or symbolic, or a combination of all three. Yet, even this is contested in many parts of the world. What for instance, is the point of origin of the United States of America? American Indians would dispute the suggestion that the declaration of independence in 1776 marked the birth of the nation. South Africa has had several moments of origin, some of which signaled a rebirth, such as in 1994. Nonetheless, an emphasis on roots has shaped the politics of identity and belonging since the emergence of the nation-state as the dominant form of global political organisation. But as LaSpina (2003:690) has observed, "globalisation shifts the emphasis on roots to an awareness of the route travelled - not only the route marking how a people migrated to their adopted country but also the historical process tracing how their identity was constructed from past to present”.

Any bid to redefine the past in narrow, exclusivist terms is likely to attempt to bend history to its will. And every sanitised history requires a villain; the antagonist against which the positive, self-righteous attributes of the protagonist can be juxtaposed. Every identity requires its "Other"; its counterpoint; its opposite. Identities are constructed and re-constructed as much in terms of what they are not as in terms of what they are; they are dialectical (Neem, 2011:66). All too often, the "Other" is also perceived as a threat; an undesirable presence that poses a menace to the identity of those doing the "othering". Cultural and/or ethnic arrogance is a powerful generator of perceptions of "Others". And while most perceptions are fictitious and informed by stereotypes and generalisations, they are incredibly powerful. So much so, the past shows that they spur people to action time and time again.

The past reveals an intriguing trajectory that begins with a history-making effort to legitimise a particular identity and its relations to those labelled its 
"Others". This can lead to cultural and/or ethnic arrogance and its attendant disparaging perceptions of those who are different. Such arrogance then breeds contempt for the "Other". Contempt feeds upon notions that the "Other" does not belong; that the "Other's" presence is somehow illegitimate. The contempt for the "Other" may even result in the steady dehumanisation of the target group. When there is sufficient contempt, there are grounds for action, which may take the form of xenophobic violence and if taken to its ultimate extreme, genocide. When a particular group of people imagine themselves as exceptional, and more victimised and persecuted than others, or having grievances specific to them, they may consider outsiders as undesirable and end up riding a wave of entitlement that absolves them from the responsibility of their actions. How the past is understood, interpreted and narrated plays a fundamental role in this process (Torbakov, 2011:213).

The African subcontinent has been a meeting place for different peoples for thousands of years; a place that has witnessed waves of human migration, settlement, displacement, dispossession and repossession. It is a place familiar with conflict. Throughout the region's human history there have been winners and losers; winners at some points have been losers at other points. After enjoying free reign for several thousand years, the San - the original indigenous peoples of the African subcontinent - lost out on land and resources when the Khoekhoe followed them south approximately 2500 years ago (Elphick \& Malherbe, 1989:4-7). Together the San and Khoekhoe lost out on land and resources when Bantu-speaking peoples also moved south in a series of migrations emanating from Central Africa, settling in southern Africa some 1000 years ago (Ross, 2008:10-21). Then European immigrants - Portuguese, Dutch, French, German, Scandinavian and British - arrived from the seventeenth century onwards, triggering a new wave of conflict over the land and its resources. But the interactions between these groups were not only conflictual. Mixed-race groups emerged through trade and cultural exchange, such as the Griqua, who are of Khoesan, slave and European descent.

The San were no easy push-over as they clashed with the Khoekhoe, the amaXhosa and the Europeans for their place in the sun. The Khoekhoe skirmished with the amaXhosa, the San and the Europeans. The amaXhosa battled the Europeans in a series of nine frontier wars from 1779 to 1879 . The amaXhosa also absorbed groups pushed south by the violent emergence of the powerful Zulu kingdom in the 1820s. The amaZulu clashed with the 
amaNdebele and later with the Voortrekkers. The Boers would eventually battle the British and by 1902, they too were a colonised people. Every group that has inflicted harm on another in South Africa has been the victim of harm itself. Modern South Africa is borne out of all of this. It is a past of struggle, the wounds of which remain fresh. However, it is also a past of entanglement, interaction and exchange. South Africa has also been created out of "processes of mobility, the boundaries of which have constantly been reinvented over time" (Nuttall, 2011:24). Indeed, while staying in place is often portrayed as the norm and migration as the exception in societies founded on the model of the nation-state, the opposite is a more valid historical representation of the South African collective's past (Geschiere, 2009:224).

\section{Victimhood and indigeneity in historical perspective}

Many, if not all, of South Africa's constituent identities may be described as victim identities. This is important to recognise, because nothing shapes identity quite like victimhood. Victim identities, ironically, appear to be capable of perpetrating incredible harm against "Others" and seem able to justify the inflicting of harm as being in the interests of defeating or overcoming their own victimhood. Every identifiable population group in South Africa can claim to have been a victim of another at some point in the country's human history. By way of example, the San were the victims of everybody else, as were the Khoekhoe. The Bantu-speaking peoples were the victims of the Boers, who were the victims of the British, who were eclipsed by resurgent Afrikaner nationalism in the twentieth century, along with everybody else. Only for the Afrikaner nationalist experiment to eventually unravel, being replaced by the current system of majority rule.

The South African past has unfolded across frontiers, both physical and metaphorical. In simple terms, a frontier is "a zone of interaction among peoples practicing different cultures” (Elphick, 1981:270). Frontiers are unstable and fluctuating. Rather than being firm boundaries regulating interaction, frontiers in the South African past have been characterised by an irregular balance of power between societies competing for dominance (Giliomee, 1981:76-119). Though certain groups have achieved ascendancy over others for certain periods of time, this has tended to be temporary. Frontiers of exchange, interaction, understanding and misunderstanding have shaped power dynamics from the earliest moments of human contact in the region. Penn (2005:13) notes that since the dawn of South Africa's 
democratic dispensation, these frontiers have been rolled back and opened up everywhere. He observes that for instance, "the Great Trek must now be seen as having achieved quite different results from those which historians once credited it with." Moreover, "the Xhosa of the eastern Cape have not only recrossed the Fish River but, for the first time, crossed the Liesbeek River as well.”

South Africa's past also shows that indigeneity is not easily defined. Appeals to indigeneity are of immense importance in a contested national space where belonging is not guaranteed to all. Indigeneity relates to the state of being indigenous. It implies an essentialist claim to ethnic or racial belonging and "entitlement to a particular territory on the basis of having been there first" (Strijdom, 2012:24). A straightforward definition of the term such as this helps to elucidate the dangers surrounding its deployment in pluralistic societies. Indigeneity may serve diverse purposes depending on the historical context. The political instrumentalisation of indigeneity is worrisome as it is an expedient tool with which to delegitimise the presence of those deemed "non-indigenous" and render such groups invisible or undesirable. Pluralistic societies also need to be wary of the phenomenon of denaturalising indigenous identity, meaning that place of birth is no guarantee of belonging or social citizenship. This is especially pertinent in post-colonial Africa. The term "indigenous" has become based on a conception of time and space linked to the colonial encounter, referring to those who were already there when the coloniers arrived. Perhaps it is time to challenge this perception? As Nyamnjoh (2007:1) remarks:

Africa offers fascinating examples of how the term 'indigenous' has been arbitrarily employed in the service of colonising forces, of how peoples have had recourse to indigeneity in their struggles against colonialism, and of how groups vying for resources and power amongst themselves have deployed competing claims to indigeneity in relation to one another.

For example, in Botswana - a non-settler colony, in the classic colonial sense of the term that equates settlers with Europeans - citizenship is guaranteed to all indigenous groups that live within its territory. However, owing to their privileged position under British colonialism, the baTswana have become the most prominent ethnic group, as is reflected in the name of the country. This has stirred protest amongst the minority baKalanga, who were present in the area before the baTswana. Though of course the San were the original aboriginal peoples of the territory, before both the baKalanga and baTswana. Even so, the San have been relegated to the very bottom of 
the hierarchy of indigeneity and are looked down upon as hunter-gatherers who have never lived productively off the land: considered a condition for entitlement to the land. The baKalanga in contrast, are stereotyped as darkerskinned "Makwerekwere" who are said to have originated from modern-day Zimbabwe (Strijdom, 2012).

The calamitous potential of an essentialist ethnic or racial monopolisation of indigeneity has perhaps been most evident in Rwanda, where a rigid ascription to the Hutu as the truly indigenous was juxtaposed alongside an equally rigid ascription to the Tutsi as foreign and invasive. Examples of rigid identity politics are not, of course, limited to Africa. In India, for example, Hindu nationalists continue to position a pre-colonial, homogenous Hindu identity as the sole criterion for belonging in the post-colonial nation-state. Indigenists attempt to recover and cultivate a "pure", pre-colonial essence of culture and tradition. On the other hand, there are those who view cultures, traditions and religions as hybrid constructs that are in constant flux owing to continuous encounters and interactions between people. Though the indigenist paradigm fails to deal with the realities of historical change and an increasingly mobile global society, it has been popular in post-colonial southern Africa as a means by which to reclaim traditions that were repressed under colonialism and apartheid (Chidester, $2000 \&$ Lawrence, 2010).

Indigeneity in South Africa is in fact layered. Waves of migration and immigration, over both land and sea, have produced degrees of indigeneity. South Africa's complex human history complicates claims to indigeneity, regardless of attempts made by political elites both past and present to regulate and solidify "indigenous" and "non-indigenous" categories from above. Contrary to the conventions of the current, ahistorical public narrative on indigeneity in South Africa, the condition is contingent and marked by degrees of overlapping. For instance, the San are the most indigenous, certainly more indigenous than the Griqua, who are also more indigenous than Afrikaners, but with whom they nonetheless share genetic and cultural similarities, as well as a language (Cavanagh, 2013:10).

When historical discourses are permeated by narrow definitions of indigeneity they pose a serious risk to any potential inclusive future for nations created by of waves of settlement. If deployed irresponsibly, the politics of indigeneity is capable of victimising those whose belonging is looked upon with doubt and suspicion. The concept also lends itself to attempts to sanitise the past, by expunging those persons, institutions and ideas considered to be of 
extraterritorial origin from the grand narrative. Though the term is meant to refer to those who inhabited a space first, as shown, the diffusion of power in a society is what ultimately determines its interpretation and application. That is why it is possible for those who were the original aboriginal peoples of a territory to find their claims to indigeneity devalued or ignored altogether. Just as an inclusive history paradigm should endeavour to embrace multiple perspectives and attitudes, so too it ought to advocate for the recognition of multiple ways of belonging. An inclusive history model can also help to resist any attempts to position certain identities and their distinctive traits as either invisible or undesirable.

Some South Africans have been rendered invisible by history in the past. For much of the twentieth century, South African history was taught as having begun with the arrival of Jan van Riebeeck in Table Bay in April 1652. The San and Khoekhoe were airbrushed out of the narrative. The San were in many ways rediscovered when the film The Gods Must Be Crazy was released in 1980. Yet, well-intended acknowledgements - such as the prominent position afforded to the San on our national coat-of-arms, along with the / Xam national motto, meaning "diverse people unite" - appear to have done little to raise awareness about their blighted history and they remain largely forgotten once again (Adhikari, 2010:21). Deny a people a place in history and it is possible to deny their legitimacy and belonging in the present.

\section{An argument for inclusive histories}

Ahonen (2001:190) has noted that "in order to be socially and politically inclusive, a history curriculum must recognise alternative narratives of the past" and that "only in this way will people with different experiences be included in a historical community." Furthermore, "where the past is both shared and multi-faceted, discussion can occur in an open space, and the future can consist of options." Changes in the field of academic history in South Africa over the course of the past 20 years or so complement an inclusive history agenda. Any dominant historiographical trend indicates the contemporary influences shaping the ideas and research interests of historians.

Contests over identity and belonging have become more pronounced in South African society since the democratic transition of the early 1990s. Citizens of all races and classes want to be heard as they interrogate and redefine apartheid-era identities (Ndebele, 2007:153-160). In light of this, the 
past has become a terrain of contestations as South African citizens search for examples of past achievements by their ethnic forebears in order to affirm their place in the present and assert their equal belonging. Though this urge may be "most acutely felt by persons dispossessed of their past", it is as applicable to someone who identifies as Afrikaner as it is of someone who identifies as Zulu or Xhosa (Comaroff \& Comaroff, 2009:9). What appears to have emerged in the public domain is a socially-conscious citizenship, but not necessarily a critical citizenship.

While the former recognises the need for transformation and that South African society is not the way it should be, the latter is an empowered position that is better equipped to imagine a more desirable, inclusive future (Spreen \& Vally, 2012:88). As noted earlier, inclusive histories can accommodate a multiplicity of voices and sub-narratives. Contrary to the uniformity of identity typically imposed by master narratives on society via broad brushstrokes of good and evil, right and wrong, moral and immoral, and which tend to lose sight of the intricacies and complexities of lived experience, smaller narratives are able to rescue individuals from obscurity and the reductionism of nationalist history. If individuals are represented as having been active agents in the unfolding of the past then it becomes possible for individuals in the present to imagine themselves in the same way. Thus, critical citizenship is an important value for history education to foster.

Critical citizenship entails self-awareness and therefore, sensitivity to subjectivity. It is possible to promote a sense of self-awareness in history curriculum if the subject goes beyond merely conveying names and dates, and incorporates the values and mentalities of past cultures (McDonald \& Underhill, 2014:62). If history curriculum can pay attention to the constructed nature of identity in the past, then learners can be sensitised to the constructed nature of their own identities in the present, as well as the identities of those around them. Indeed, as Sieborger and Reid (1995:172) have contended, "more important than teaching identity, [is] teaching how identity [is] formed." This is an ideal scenario and best understood as a project of possibility, whereby attempts to instill a sense of critical citizenship and self-awareness will resonate to varying degrees with different individuals, if at all (Simon, 1992:22). Still, it is worth making the effort.

Representations of the past that highlight subjectivities and individualised experiences will have to deal with multiple discourses and recognise the worth of plural meanings in a pluralistic society (Davis \& Steyn, 2012:29). 
By valuing alternative and multiple interpretations of lived experience in the past, inclusive histories broaden and deepen historical understanding and also create new possibilities for the acquisition of more nuanced historical knowledge. Though the objectives of inclusive history are fairly modest in the sense that it aims to encourage a sensitivity towards other perspectives and an understanding of alternative viewpoints, its ideals do not sit neatly with those of many modern nation-states.

Obstacles to realising the ideals of an inclusive history epistemology include: an authoritarian political culture; ethnic- or race-centric determinants of belonging; nationalist history; and common misconceptions about what history is. Even though a unified, national history curriculum based on a select number of approved texts may seem like the sensible option for a nationstate with a divisive past and a current identity crisis, such as South Africa, such an agenda is actually counter-productive. As long as societies continue to experience insecurities regarding their national identity - especially in contexts shaped by recent conflictual pasts - the prospects for a unified history curriculum to take hold and find widespread buy-in are limited at best. Few such history curriculums would satisfy the majority of any national population anywhere in the world.

The question then is whether it is possible to imagine a unified nation for the future without a unified national history curriculum? In response to this question, it is worth noting that history textbooks are not the sole source of historical information for school learners; textbooks do not exist in a social vacuum. There are multiple (unreliable) sources of historical knowledge that may be accessed in a variety of (unreliable) ways. It is perhaps disheartening for historians to acknowledge that academic history is not the only, or even the most important, source of information about the past (Allen, 2000:294). Different sources of historical knowledge compete with each other for influence and while it is important to make learners aware of this, it is also crucial to promote inclusive histories beyond just the classroom or lecture hall (Brookbanks, 2014). Nonetheless, history textbooks will play an important role in disseminating ideas pertaining to inclusive histories and identities. In spite of sound intentions on the part of curriculum theorists to avoid "narrow conceptions of the past", as Van Eeden (2010:118) asserts, much of the responsibility for promoting inclusiveness rests with the textbook developers and publishers; "for providing substance and direction to curriculum content in the form of a variety of historical enquiry genres and voices" (Van Eeden, 
2010:118).

In terms of promoting a unified nation for the future, the education system as a whole is going to play a foundational role (Staeheli \& Hammett, 2013:33). Therefore, in order for the values of inclusive history to have any chance of resonating with and impacting on learners, a consistent discourse of inclusivity and multi-perspectivity needs to be upheld across the curriculum landscape. An inclusive history praxis will sit comfortably within a national school curriculum that encourages national cosmopolitanism as a tool for social (re) production. Within a paradigmatic approach of national cosmopolitanism, South Africa's past forms part of the nation's particular historical record, but it does not define or determine the nation's current collective identity; even as it fully acknowledges the historical roots of many of the challenges facing the country, such as profound inequality and continuing forms of spatial and social segregation (Staeheli \& Hammett, 2013:34).

\section{Conclusion: What history does South Africa's future deserve?}

To refer to history in the singular is hugely problematic and arguably flawed. Any historical work that begins with the title: "The History of", or even more problematically, "The Definitive History of", ought to be treated with a healthy dose of skepticism. There is no one history, but multiple histories, of peoples, places, processes and events. At best, we can know a history of something and that particular version may change over time, as the present changes and as present priorities and prerogatives, of the economic, political and socio-cultural varieties, shift. As such, history changes; it is never static. And therefore it is always necessary for a society that strives towards inclusivity to ask: "What history does our future deserve"?

The ways in which the past is re-represented are representative of the dominant ideologies of the present. Therefore, if South Africa remains committed to pursuing a future that embraces the inclusive ethos of its constitutional democracy, it does not require a history that some want, or that some feel entitled to force on others, but it is in need of a history that reflects the multiple journeys that the collective complexities, entanglements and contests that constitute its social fabric have taken on the way to the present. A sanitised version of the past risks being informed by a combination of political dogmatism and socio-cultural bias that aim to provide historical legitimacy for a cause and that exclude those aspects of the past that do not 
neatly fit. More importantly, and more dangerously, an exclusivist historical narrative will also exclude those deemed outsiders; those not belonging; those considered to be an illegitimate presence.

\section{References}

Adhikari, M 2010. The anatomy of a South African genocide: The extermination of the Cape San Peoples. Cape Town: UCT Press.

Ahonen, S 2001. Politics of identity through history curriculum: Narratives of the past for social exclusion - or inclusion? Journal of Curriculum Studies, 33(2):179-194.

Allen, G 2000. Is there a baby is this bathwater? Disquieting thoughts on the value of content in history. South African Historical Journal, 42(1):290-306.

Andreasson, S 2010. Confronting the settler legacy: Indigenisation and transformation in South Africa and Zimbabwe. Political Geography, 29:424-433.

Brookbanks, GJ 2014. Inspiring history learners: Getting the recipe right in the history classroom. Yesterday\&Today, 12:90-104.

Cavanagh, E 2013. Settler colonialism and land rights in South Africa: Possession and dispossession on the Orange River. London \& New York: Palgrave Macmillan.

Chidester, D 2000. Colonialism. In: W Braun \& R McCutcheon (eds.). Guide to the study of religion. London: Cassell.

Chisholm, L 2008. Migration, citizenship and South African history textbooks. South African Historical Journal, 60(3):353-374.

Comaroff, JL \& Comaroff, J 2009. Ethnicity, inc. Scottsville: University of KwaZulu-Natal Press.

Davis, D \& Steyn, M 2012. Teaching social justice: Reframing some common pedagogical assumptions. Perspectives in Education, 30(4):29-38.

Elphick, R 1981. Africans and the Christian campaign in southern Africa. In: H Lamar \& L Thompson (eds.). The frontier in history: North American and southern Africa compared. New Haven \& London: Yale University Press.

Elphick, R \& Malherbe, VC 1989. The Khoisan to 1828. In: R Elphick \& H Giliomee (eds.). The Shaping of South African Society, 1652-1840. Cape Town: Maskew Miller Longman. 
Geschiere, P 2009. The perils of belonging: Autochthony, citizenship and exclusion in Africa and Europe. Chicago: University of Chicago Press.

Giliomee, H 1981. Processes in the development of the southern African frontier. In: H Lamar \& L Thompson (eds.). The frontier in history: North American and southern Africa compared. New Haven \& London: Yale University Press.

LaSpina, JA 2003. Designing diversity: Globalisation, textbooks, and the story of nations. Journal of Curriculum Studies, 35(6):667-696.

Lawrence, B 2010. Legislating identity: Colonialism, land and indigenous legacies. In: M Wetherell \& CT Mohanty (eds.). The SAGE handbook of identities. London: SAGE.

McDonald, J \& Underhill, J 2014. "Making history familiar": The past in service of selfawareness and critical citizenship. Yesterday \& Today, 11:54-71.

McMillan, M 2008. The uses and abuses of history. London: Profile Books.

Ndebele, NS 2007. Fine lines from the box: Further thoughts about our country. Johannesburg: Umuzi.

Ndlovu, M 2013. Mobilising history for nation-building in South Africa: A decolonial perspective. Yesterday\&Today, 9:1-12.

Neem, JN 2011. American history in a global age. History and Theory, 50:41-70.

Nuttall, S 2011. Entanglement: Literary and cultural reflections on post-apartheid. Johannesburg: Wits University Press.

Nuttall, T \& Wright, J 2000. Probing the predicaments of academic history in contemporary South Africa. South African Historical Journal, 42:26-48.

Nyamnjoh, F 2007. Ever-diminishing circles: The paradoxes of belonging in Botswana. In: M De la Cadena \& O Stern (eds.). Indigenous experience today. Oxford: Berg.

Penn, N 2005. The forgotten frontier: Colonist and Khoisan on the Cape's northern frontier in the $18^{\text {th }}$ century. Cape Town: Double Storey Books \& Athens: Ohio University Press.

Ross, R 2008. A concise history of South Africa. $2^{\text {nd }}$ edition. Cambridge: Cambridge University Press.

Siebörger, R \& Reid, J 1995. Textbooks and the school history curriculum. South African Historical Journal. 33(1):169-177. 
Simon, R 1992. Teaching against the grain: Texts for pedagogy of possibility. New York: Bergen \& Garvey.

Spreen, CA \& Vally, S 2012. The curriculum and citizenship education in the context of inequality: Seeking a praxis of hope. Perspectives in Education, 30(4):88-97.

Staeheli, LA \& Hammett, D 2013. "For the future of the nation": Citizenship, nation and education in South Africa. Political Geography, 32:32-41.

Strijdom, JM 2012. Problems with indigeneity: Fragmentation, discrimination and exclusion in post-colonial African states. Image \& Text, 19:24-32.

Torbakov, I 2011. History, memory and national identity: Understanding the politics of history and memory wars in post-Soviet lands. Demokratizatsiya, 19(3):209232.

Van Eeden, E 2010. South Africa's revised history curriculum on globalism and national narratives in grade 12 textbooks. Historia, 55(1):110-124. 